\title{
EVALUATION OF FENTANYL AS AN ADJUVANT TO BUPIVACAINE IN ULTRA SOUND GUIDED TRANSVERSUS ABDOMINIS PLANE BLOCK FOR POSTOPERATIVE ANALGESIA IN PATIENTS UNDERGOING ABDOMINAL HYSTERECTOMY
}

\author{
Donkada Rajasekhar1, T. Mohan Sankarji Maharaj²
}

${ }^{1}$ Associate Professor, Department of Anaesthesiology, GIMSAR, Visakhapatnam, Andhra Pradesh, India.

${ }^{2}$ Assistant Professor, Department of Anaesthesiology, GIMSAR, Visakhapatnam, Andhra Pradesh, India.

ABSTRACT
BACKGROUND
The transversus abdominis plane (TAP) block is a regional analgesia technique that forms part of the multimodal approach to
postoperative pain management for abdominal surgeries. Local anaesthetics like Bupivacaine with longer duration are preferred
for TAP block. However, even that is insufficient to match the duration of postoperative pain in abdominal surgeries. The current
study was to evaluate if Fentanyl as an adjuvant to bupivacaine in ultrasound guided TAP block improves the duration and quality
of postoperative analgesia following abdominal hysterectomy.

\section{METHODS}

Forty four patients, aged 18-60 years of American Society of Anaesthesiologist (ASA) Physical status I or II, posted for elective open abdominal hysterectomy under general anaesthesia were recruited by convenience sampling technique, to receive TAP block using $19.5 \mathrm{ml}$ of bupivacaine hydrochloride $0.25 \%+0.5 \mathrm{ml}$ saline $0.9 \%$ (Group B, $\mathrm{n}=22$ ) or $19.5 \mathrm{ml}$ of bupivacaine hydrochloride $0.25 \%$ $+0.5 \mathrm{ml}$ Fentanyl (25 microgram)( Group BF, $\mathrm{n}=22$ ), after the completion of surgery but prior to extubation. Visual analogue scale (VAS) scores at rest and movement were assessed on the emergence, at 0, 2, 4, 6, 12 and 24-hours (h). Time to First Analgesic (TFA), when VAS $\geq 4 \mathrm{~cm}(\geq 40 \mathrm{~mm})$ or on demand was noted. The incidence of postoperative nausea and vomiting (PONV) and sedation were compared.

\section{RESULTS}

VAS score was significantly lower in the study group, at rest at $2 \mathrm{~h}(14.68 \mathrm{vs} .20 .63, \mathrm{p}=0.006), 4 \mathrm{~h}(24.46 \mathrm{vs.} 24.77, \mathrm{p}=0.02), 6 \mathrm{~h}$ ( 22.27 vs. $28.45, \mathrm{p}=0.002)$ and $12 \mathrm{~h}(18.90$ vs. $21.00, \mathrm{p}=0.043)$ and that with movement, at $2 \mathrm{~h}(20.45 \mathrm{vs.} 25.86, \mathrm{p}=0.006), 4 \mathrm{~h}(25.23$ vs. $30.95, \mathrm{p}=0.001)$ and $6 \mathrm{~h}(29.14$ vs. $33.90, \mathrm{p}=0.006)$. TFA was significantly lower in study group (398.73 minutes vs. 537.09 minutes, $\mathrm{p}<0.001)$. PONV was comparable in both groups. Sedation score in study group was relatively significant at 4 hours, $(\mathrm{p}<0.001)$.

\section{CONCLUSIONS}

Fentanyl as an adjuvant to bupivacaine in ultrasound guided transversus abdominis plane block, following abdominal hysterectomy under general anaesthesia improves the quality and duration of postoperative analgesia without any major adverse effects.

\section{KEY WORDS}

Bupivacaine, Fentanyl, Ultra Sound Guidance, Transversus Abdominis Plane Block, Adjuvant, Analgesia

HOW TO CITE THIS ARTICLE: Rajasekhar D, Maharaj TMS. Evaluation of fentanyl as an adjuvant to bupivacaine in ultra sound guided transversus abdominis plane block for postoperative analgesia in patients undergoing abdominal hysterectomy. J. Evolution Med. Dent. Sci. 2019;8(30):2407-2411, DOI: 10.14260/jemds/2019/527

\section{BACKGROUND}

Transversus abdominis plane (TAP) block is a regional anaesthesia technique that forms part of the multimodal approach to postoperative pain management and can provide analgesia for abdominal surgeries like abdominal hysterectomy. Multimodal analgesia is defined as simultaneous use of different classes of modes of analgesics that modulate different pathways and receptors in order to provide superior pain relief. It provides superior pain relief with lower doses of these agents like opoids. ${ }^{1,2}$

'Financial or Other Competing Interest': None.

Submission 29-05-2019, Peer Review 08-07-2019,

Acceptance 15-07-2019, Published 29-07-2019.

Corresponding Author:

T. Mohan Sankarji Maharaj,

Flat No. 101, Empire Estate,

Gokhale Road, GIMSAR,

Visakapatnam-530002, Andhra Pradesh, India.

E-mail:dr.mohanmaharaj@gmail.com

DOI: $10.14260 /$ jemds $/ 2019 / 527$
These in turn may facilitate earlier mobilization after surgery, earlier discharge to outpatient care and decreased cost of care.3,4 The block provides analgesia for the skin, subcutaneous tissue, muscles and parietal peritoneum and the Nonsteroidal antiinflammatory drugs (NSAID) along with or without opioids provides analgesia for visceral pain. The use of ultrasound has improved the success rate and accuracy of regional blocks. Ultrasound guidance offers a safe and effective means of correct needle placement and adequate spread of local anaesthetic in Tap Block.5,6 Local anaesthetics with longer duration are preferred for the transversus abdominis plane block. In this regard, Bupivacaine has significantly longer analgesic duration compared to other commonly used local anaesthetics. But, even that is insufficient to match the duration of postoperative pain. Many adjuvants including fentanyl have been studied for local anaesthetics to extend the duration of postoperative analgesia following regional blocks. ${ }^{7}$ 


\section{Aims and Objectives}

The current study was done to evaluate as to whether Fentanyl as an adjuvant to local anaesthetic bupivacaine improves the quality and duration postoperative analgesia of transversus abdominis plane block in abdominal hysterectomy.

The Primary objective is to compare the duration and quality of post-operative analgesia of Transversus abdominis plane blocks, with and without Fentanyl as adjuvant to Bupivacaine, in abdominal hysterectomy patients. The secondary objective is to compare the post-operative nausea and vomiting and sedation levels following Transversus abdominis plane block and without Fentanyl as adjuvant to Bupivacaine, in abdominal hysterectomy patients.

\section{METHODS}

This is an interventional study with Comparison Grouping. The study was formulated after obtaining approval from the Institutional Research and Ethical Committee and written and informed consent from patients were secured from GITAM Institute of Medical Sciences and Research Visakhapatnam.

\section{Time Period}

January 2015 March 2017.

\section{Sample Size}

was estimated from duration of postoperative analgesia in review literatures as measured by time to first analgesia was found to be in, control group a mean time of 325.4 [SD=36.6] minutes and in study group a mean time of 459.8 [SD=75.3] minutes. ${ }^{8}$ And assuming a difference of 60 minutes in the proposed study, the sample size was thus figured out to be 22 in either group.

\section{Inclusion Criteria}

44 patients aged 18-60 years of American Society of Anaesthesiologists (ASA) Grade I and II posted for abdominal hysterectomy by suprapubic transverse incision under general anaesthesia. Patient allergic to amide local anaesthetics or any of the study drugs, with infection at proposed injection site, already on an analgesic drug in past 24-hours before induction, with deranged coagulation profile and patients with psychiatric illness or substance abuse who are unreliable in their reporting of pain were excluded from the study.

\section{Convenience Sampling}

Those patients satisfying inclusion and exclusion criteria were included in study till desired sample size and allotted to Group B $(\mathrm{n}=22)$ to receive Ultrasound guided TAP block with $19.5 \mathrm{ml}$ of bupivacaine hydrochloride $0.25 \%+0.5 \mathrm{ml}$ normal saline $0.9 \%$ on either side and Group BF $(n=22)$ to receive Ultrasound guided TAP block with or $19.5 \mathrm{ml}$ of bupivacaine hydrochloride $0.25 \%+0.5 \mathrm{ml}$ Fentanyl (25 microgram) on either side.

A thorough preanaesthetic evaluation was done, which included detailed history taking, General examination including Vitals, Anthropometric measurements of Weight, Height and Body Mass Index, Airway assessment and Systemic examination.

\section{RESULTS}

Demographic data and operational characteristics were initially compared.

\begin{tabular}{|c|c|c|c|}
\hline Parameters & $\begin{array}{c}\text { Group BF } \\
\text { Mean (SD) }\end{array}$ & $\begin{array}{c}\text { Group B } \\
\text { Mean (SD) }\end{array}$ & p Value* \\
\hline Age (years) & $44.32(5.85)$ & $44.41(4.80)$ & 0.972 \\
\hline Weight $(\mathrm{kg})$ & $62.5(9.04)$ & $65.23(8.16)$ & 0.372 \\
\hline Height $(\mathrm{cm})$ & $163.19(8.29)$ & $160.5(8.68)$ & 0.280 \\
\hline BMI $\left(\mathrm{kg} / \mathrm{m}^{2}\right)$ & $23.35(1.78)$ & $25.30(2.27)$ & $0.003^{\#}$ \\
\hline Duration of Surgery (Minutes) & $125.77(23.34)$ & $133.5(26.60)$ & 0.488 \\
\hline Duration of Anaesthesia (Minutes) & $147.32(24.86)$ & $158.32(25.19)$ & 0.188 \\
\hline Table 1. Demographic Data and Operative Characteristics of \\
Patients in The Two Groups \\
\hline
\end{tabular}

\begin{tabular}{|c|c|c|c|}
\hline $\begin{array}{c}\text { Time of } \\
\text { Observation }\end{array}$ & $\begin{array}{c}\text { Group BF Mean } \\
\text { (SD) }\end{array}$ & $\begin{array}{c}\text { Group B Mean } \\
\text { (SD) }\end{array}$ & p Value* \\
\hline 0-hours & $5.64(4.62)$ & $6.45(4.69)$ & 0.457 \\
\hline 2-hours & $14.68(6.24)$ & $20.63(6.44)$ & $0.006^{\#}$ \\
\hline 4-hours & $24.46(22.31)$ & $24.77(4.92)$ & $.020^{\#}$ \\
\hline 6-hours & $22.27(6.76)$ & $28.45(4.86)$ & $.002^{\#}$ \\
\hline 12-hours & $18.90(3.42)$ & $21.00(3.31)$ & $.043^{\#}$ \\
\hline 24-hours & $19.63(3.81)$ & $20.91(3.13)$ & .309 \\
\hline \multicolumn{4}{|c|}{ Table 2. Comparison between the Two Groups According to } \\
VAS Score at Rest (mm)
\end{tabular}

\begin{tabular}{|c|c|c|c|}
\hline $\begin{array}{c}\text { Time of } \\
\text { Observation }\end{array}$ & $\begin{array}{c}\text { Group BF Mean } \\
\text { (SD) }\end{array}$ & $\begin{array}{c}\text { Group B Mean } \\
\text { (SD) }\end{array}$ & p Value* \\
\hline 0-hours & $9.45(6.03)$ & $10.14(4.81)$ & .698 \\
\hline 2-hours & $20.45(6.28)$ & $25.86(6.07)$ & $0.006^{\#}$ \\
\hline 4-hours & $25.23(4.89)$ & $30.95(4.76)$ & $.001^{\#}$ \\
\hline 6-hours & $29.14(6.76)$ & $33.90(4.41)$ & $.006^{\#}$ \\
\hline 12-hours & $25.68(3.29)$ & $26.45(2.87)$ & 0.338 \\
\hline 24-hours & $20.27(3.52)$ & $19.64(3.81)$ & 0.232 \\
\hline \multicolumn{4}{|c|}{ Table 3. Comparison Between the Two Groups According to } \\
VAS at Movement (mm)
\end{tabular}

\begin{tabular}{|c|c|c|c|}
\hline Group & Mean (Minutes) & SD & p Value \\
\hline BF & 537.09 & 60.68 & $<0.001$ \\
\hline B & 398.73 & 62.94 & \\
\hline \multicolumn{3}{|c|}{ Table 4. Comparison Between the Two Groups According to } \\
Time to First Analgesic (TFA) in Minutes \\
\hline
\end{tabular}

\begin{tabular}{|c|c|c|c|}
\hline Time of observation & $\begin{array}{c}\text { Group BF } \\
\text { Mean (SD) }\end{array}$ & $\begin{array}{c}\text { Group B Mean } \\
\text { (SD) }\end{array}$ & p Value* \\
\hline 0-hours & $2.28(.43)$ & $2.14(.35)$ & 0.44 \\
\hline 2-hours & $1.95(.21)$ & $1.77(.43)$ & 0.082 \\
\hline 4-hours & $1.77(.43)$ & $1.27(.70)$ & $0.010^{\#}$ \\
\hline 6-hours & $1.32(.57)$ & $1.00(.62)$ & 0.087 \\
\hline 12-hours & $.82(.39)$ & $77(.43)$ & 0.712 \\
\hline 24-hours & $.45(.51)$ & $.28(.43)$ & 0.116 \\
\hline \multicolumn{4}{|c|}{ Table 5. Comparison Between the Two Groups According to } \\
Sedation Score \\
\hline
\end{tabular}

\begin{tabular}{|c|c|c|c|}
\hline & PONV & No PONV & p Value \\
\hline Group BF & $4(18.2 \%)$ & $18(81.8 \%)$ & \multirow{2}{*}{0.664} \\
\hline Group B & $2(9.1 \%)$ & $20(90.91 \%)$ & \\
\hline \multicolumn{2}{|c|}{ Table 6. Comparison Between the Two Groups According to } \\
Postoperative Nausea and Vomiting (PONV) \\
\hline
\end{tabular}

Routine investigations like Hemogram, Renal function tests, Liver function tests, Bleeding time, Clotting time, Prothrombin time, International normalized ratio (INR), $\mathrm{X}$ ray Chest Posterior Anterior view and Electrocardiogram were done and reviewed in all patients. Patients were sent for pre-test counseling and screening for HIV, HCV, HBsAg and VDRL tests.

During the pre-anaesthetic assessment, visual analog scale (VAS) of 0 to $10 \mathrm{~cm}$ for assessment of pain, with $0 \mathrm{~cm}$ corresponding to no pain and $10 \mathrm{~cm}$ to the worst pain imaginable was taught to them. They were also instructed to demand for analgesia as and when required.

All patients were kept Nil Per Oral for eight-hours prior to surgery. They were pre-medicated with Tab. Alprazolam 0.5 
mg, Tab. Metoclopramide $10 \mathrm{mg}$ and Tab. Ranitidine $150 \mathrm{mg}$ on the previous night and two-hours prior to Surgery.

Upon arrival at the operation theatre, standard monitoring was instituted using a multivital parameter monitor for continuous electrocardiography, blood oxygen saturation and non-invasive blood pressure. Base line measurements were noted. A 20 Gauge intravenous cannula was secured on the dorsum of non-dominant hand and $0.9 \%$ sodium chloride or normal saline was commenced.

All patients were pre-medicated with Inj. Midazolam 0.02 $\mathrm{mg} / \mathrm{kg}$ and Inj. Ondansetron $4 \mathrm{mg}$ about 5 minutes before induction of anaesthesia. Pre-oxygenation was done with $100 \%$ oxygen by facemask, with the patient in supine position. Anaesthesia was induced with Inj. Morphine 0.15 $\mathrm{mg} / \mathrm{kg}$ and Inj. Propofol 1-2.5 mg/kg was injected slowly titrated till loss of verbal communication. Inj. Succinylcholine $1.5 \mathrm{mg} / \mathrm{kg}$ was administered to facilitate intubation. Direct Laryngoscopy was performed using Macintosh laryngoscope and intubated with appropriate size cuffed endotracheal tube. Endotracheal tube was fixed and connected to ventilator after checking bilateral equal air entry. Patients were mechanically ventilated, and anaesthesia maintained with Sevoflurane at 1.5- $2 \%$ using $33 \%$ oxygen and $66 \%$ nitrous oxide. Muscle relaxation was maintained with Vecuronium $0.1 \mathrm{mg} / \mathrm{kg}$ initial bolus dose and maintained with increments of $0.025 \mathrm{mg} / \mathrm{kg}$.

Fasting Fluid deficit was also corrected by maintenance fluids. Blood loss was approximately calculated from mops and suction drain bottles and losses up to the transfusion threshold were replaced with $3 \mathrm{ml}$ of Ringer's lactate for each $\mathrm{ml}$ of blood loss.

Acetaminophen 1-gram intravenous infusion was given over 30 minutes prior to completion of surgery. After completion of surgery, ultrasound guided TAP block was performed to all patients on both sides according to the group.

Portable Ultrasound Machine (GE Healthcare, Venue 40 Anaesthesia) with wide band linear probe (12L-SC) was used for the performance of TAP blocks. With the patient supine, under strict aseptic precautions with the skin disinfected and the probe covered with sterile cover and sleeve, the transducer was placed on the skin at the anterior axillary line, between the costal margin and the iliac crest. The transducer was slid slightly cephalad or caudal to aid in visualisation of the three muscle layers of EOM, IOM and TAM lying parallel to each other. Once the transverse abdominal plane was identified, transducer position was kept still and a skin wheal was made 2 to $3 \mathrm{~cm}$ medial to it, with local anaesthetic. The 23 Gauge spinal needle was inserted in-plane oriented medial to lateral. The needle was directed through the subcutaneous tissue, EOM, and IOM, under real time guidance. A "pop" was appreciated as the needle tip entered the plane piercing the fascia. $0.9 \%$ normal saline $1 \mathrm{ml}$ was injected with slight movement to optimise the needle tip position. Once the needle tip is correctly placed and after careful aspiration to rule out malposition of needle tip, $19.5 \mathrm{ml}$ of bupivacaine hydrochloride $0.25 \%+0.5 \mathrm{ml}$ saline $0.9 \%$ or $19.5 \mathrm{ml}$ of bupivacaine hydrochloride $0.25 \%+0.5 \mathrm{ml}$ Fentanyl $(25$ microgram) was injected according to the group.

After the completion of TAP block on both sides, inhalational agent was discontinued, and reversal of muscle relaxation was done with Neostigmine $0.05 \mathrm{mg} / \mathrm{kg}$ and
Glycopyrrolate $0.01 \mathrm{mg} / \mathrm{kg}$. Then the patient was extubated and transferred to post anaesthesia care unit.

After the patient has adequately recovered from anaesthesia, and was able to assess pain, postsurgical analgesia was assessed with VAS 0 to $10 \mathrm{~cm}(100 \mathrm{~mm})$ at rest and movement as defined by flexion of both knees, at 0 -hour, 2-hour, 4-hour, 6-hour, 12-hour and 24-hours and whenever the patient complained of pain.

When VAS score exceeded $>4 \mathrm{~cm}(40 \mathrm{~mm})$ or when the patients demanded for the first analgesic, Injection Tramadol $2 \mathrm{mg} / \mathrm{kg}$ intravenous was given at, whichever was earlier and the Time to First Analgesic (TFA) was noted as from the time of full recovery from anaesthesia.

The incidence of postoperative nausea and vomiting (PONV) was studied for the first 24-hours. Nausea was be measured using a categorical scoring system PONV score. (None $=0$, mild $=1$, moderate $=2$; severe $=3$ ). Rescue antiemetic Injection Ondansetron $4 \mathrm{mg}$ was given as and when the patient complained of nausea or vomiting.

The level of sedation was assessed using University of Michigan Sedation score $(0=$ awake and alert, $1=$ minimal sedated with appropriate response to verbal conversation or sound, 2=moderately sedated with arousability on light tactile stimulation or verbal command, $3=$ Deeply sedated with arousability on significant physical stimulation, $4=$ unarousable)

Heart rate (HR), Systolic Blood Pressure (SBP), and Diastolic Blood Pressure (DBP) were monitored over time and noted at 0-hour, 2-hour, 4-hour, 3-hour, 12-hour and 24hours.

All patients were observed for any other side effects like hypotension hypercapnia, bradycardia and allergic reactions.

\section{Analysis of Data}

Statistical analysis was performed using Statistical Package for Social Sciences (SPSS) software version 17.0 (SPSS Inc., Chicago, IL, USA). To determine whether data sets differed from normal distribution, one sample Kolmogorov Smirnov test was used. The non-normally distributed data were analysed using the Mann Whitney $\mathrm{U}$ test and categorical data were analysed using the Chi square test. p Value less than 0.05 was considered statistically significant.

Duration of postoperative analgesia as measured by time to first analgesic (TFA) was analysed by applying MannWhitney U test to the mean value. Quality of postoperative analgesia as measured by Visual analog scale (VAS score) at rest and movement was analysed by applying Unpaired t- test to the mean value of both. Proportion of patients with postoperative nausea and vomiting was compared using Chisquare tests. Sedation levels of patient were compared using Mann-Whitney U test to the mean value.

The mean VAS score at rest was lower in Group BF compared to Group B at 0-hour, 2-hour, 6-hour, 12-hour and 24-hour. The difference in VAS scores at rest between Group BF and Group B was statistically significant at 2-hour ( $\mathrm{p}=$ $0.006<0.05)$, 4-hour ( $\mathrm{p}=0.02<0.05), 6$-hour $(\mathrm{p}=0.002<$ $0.05)$ and 12-hour ( $\mathrm{p}=0.043<0.05)$.

The mean VAS score at Movement was lower in Group BF compared to Group B at 0-hour, 2-hour, 6-hour, and 12-hour. VAS score at movement in 24-hour was higher in Group BF compared to Group B. The difference in VAS scores at Movement, between Group BF and Group B was statistically 
Significant at 2-hour ( $\mathrm{p}=0.006<0.05), 4$-hour $(\mathrm{p}=0.001<$ $0.05)$, and 6-hours ( $\mathrm{p}=0.006<0.05)$.

The mean Time to first Analgesia (TFA) in Group BF and Group B were $537.09 \pm 60.68$ minutes and $398.73 \pm 62.94$ minutes respectively. The difference in Time to first Analgesia (TFA) between the two groups was statistically significant. ( $p$ Value $0.001<0.05$ )

The mean Sedation score was higher in Group BF compared to Group B at 0-hour, 2-hour, 4-hour, 6-hour, 12hour and 24-hours. The difference in Sedation scores, between Group BF and Group B was statistically significant at 4-hour ( $\mathrm{p}=0.01$

$$
<0.05) \text {. }
$$

The percentage of incidence of postoperative nausea and vomiting (PONV) in Group BF and Group B were 18.2\% and 9.1\% respectively. The difference in percentage of the incidence of postoperative nausea and vomiting (PONV) between the two groups was not statistically significant $(p=0.664>0.05)$.

\section{DISCUSSION}

The transversus abdominis plane (TAP) block is a novel rapidly expanding regional anaesthesia technique, that provides analgesia following abdominal surgeries. Local anaesthetics like bupivacaine with relatively longer duration of action are used in TAP block, however even that is insufficient to match the duration and intensity of postoperative pain following abdominal surgeries.

Few adjuvants to Bupivacaine have been studied for TAP block and have shown to improve the postoperative pain outcome. Fentanyl as adjuvant to bupivacaine in TAP bock has not yet been evaluated to the best of our knowledge though, fentanyl to bupivacaine in peripheral nerve blocks have shown promising results. Both groups were comparable regarding age, weight and height $(\mathrm{P}>0.05)$.The two groups were comparable with respect to their physical status classification according to American Society of Anesthesiologists (ASA). The two groups were comparable according to the duration of surgery and duration of anaesthesia.

The mean VAS score at rest was lower in Group BF compared to Group B at 0-hour, 2-hour, 4-hour, 6-hour, 12hour and 24-hour. The difference in VAS scores at rest between Group BF and Group B was statistically significant at 2-hour ( $\mathrm{p}=0.006<0.05)$ and 4-hour ( $\mathrm{p}=0.02<0.05)$, 6-hour $(p=0.002<0.05)$ and 12 -hour $(p=0.043<0.05)$. The mean VAS score at Movement was lower in Group BF compared to Group B at 0-hour, 2-hour, 4-hour, 6-hour and 12-hour. VAS score at movement in 24-hour was higher in Group BF compared to Group B. The difference in VAS scores at Movement, between Group BF and Group B was statistically significant at 2 -hour ( $p=0.006<0.05)$, 4-hour $(\mathrm{p}=0.001<0.05)$, and 6-hours ( $\mathrm{p}=0.006<0.05)$

All the patients in the study, irrespective of the group had demanded for rescue analgesic in the post-operative period, before the VAS Score exceeded $40 \mathrm{~mm}(4 \mathrm{~cm})$. The mean Time to first Analgesic (TFA) in Group BF and Group B were $537.09 \pm 60.68$ minutes and $398.73 \pm 62.94$ minutes respectively. The difference in Time to first Analgesia (TFA) between the two groups was statistically significant. ( $p$ Value $<0.001$ ).
In Ammar et al study, when dexamethasone was added to bupivacaine for TAP block for postoperative analgesia in abdominal hysterectomy under general anaesthesia, the pain VAS score at movement was significantly lower in the study group, at the postoperative 2-hour ( 4.9 vs. $28.1, \mathrm{p}=0.01$ ), 4 hour (12.2 vs. $31.1, \mathrm{p}=0.01)$ and 12 -hour (15.7 vs. 25.4, $\mathrm{p}=0.02$ ). TFA was significantly longer in the dexamethasone group (459.8 vs. $325.4 \mathrm{~min}, \mathrm{p}=0.002$ ). ${ }^{8}$

In Almarakbi etal study, dexmedetomidine was added to bupivacaine for TAP block for postoperative analgesia in abdominal hysterectomy under general anaesthesia, the pain VAS scores at rest and movement were significantly lower in study group, in the first 8-hours post-operatively $(\mathrm{P}<$ 0.001). ${ }^{9}$

Both these studies were done in general anaesthesia and was induced with propofol and fentanyl, and the ultrasound guided TAP block was given prior to surgical incision and intravenous analgesic regimens were different from our study, which makes drawing a comparison not possible.

In Rana et al study, where in Magnesium sulphate was evaluated as adjuvant to bupivacaine in TAP block for abdominal hysterectomy, the surgery was done under subarachnoid block. ${ }^{10}$

The mean Sedation score was higher in Group BF compared to Group B at 0-hour, 2-hour, 4-hour, 6-hour, 12hour and 24-hours. The difference in Sedation scores, between Group BF and Group B was statistically significant at 4-hour ( $\mathrm{p}=0.01<0.05)$.

The percentage of incidence of postoperative nausea and vomiting (PONV) in Group BF and Group B were $18.2 \%$ and $9.1 \%$ respectively. The difference in percentage of the incidence of postoperative nausea and vomiting (PONV) between the two groups was not statistically significant $(\mathrm{p}=$ $0.664>0.05$ )

In Wang LZ et al study, when Fentanyl was added to ropivacaine in ultrasound guided TAP block for caesarean section under subarachnoid block, there was no improvement in postoperative pain outcome and no significant differences in the postoperative nausea and vomiting sedation levels. ${ }^{7}$ In our study, the sedation scores were higher in group BF compared to Group B at 0-hour, 2hour, 4-hour, 6-hour, 12-hour and 24-hour. The difference in Sedation scores, between Group BF and Group B was statistically significant at 4 -hour $(\mathrm{p}=0.01<0.05)$. However, the mean values of sedation score in study group, was always less than score of 3 , at which the patient is moderately sedated, with arousability on light tactile stimulation or verbal command. Sedation levels in study group were hence not clinically significant to cause adverse outcomes like pulmonary aspiration and respiratory failure. TAP block is relatively easy technique to obtain optimal images and direct needle under real time ultrasound guidance. ${ }^{6}$

\section{CONCLUSIONS}

Addition of $0.5 \mathrm{ml}$ Fentanyl (25 microgram) to $19.5 \mathrm{ml}$ of bupivacaine hydrochloride $0.25 \%$, in ultrasound guided transversus abdominis plane block, following abdominal hysterectomy under general anaesthesia, improved the quality and duration of postoperative analgesia without any major adverse effects. 


\section{REFERENCES}

[1] White PF. The changing role of non-opioid analgesic techniques in the management of postoperative pain. Anaesth Analg 2005;101(Suppl 5):s5-22.

[2] Ritchey RM. Optimizing postoperative pain management. Cleve Clin J Med 2006;(73 Suppl 1):s726.

[3] Elvir-Lazo OL, White PF. Postoperative pain management after ambulatory surgery: role of multimodal analgesia. Anaesthesiol Clin 2010;28(2):217-24.

[4] Wu CL, Fleisher LA. Outcomes research in regional anaesthesia and analgesia. Anaesth Analg 2000;91(5):1232-42.

[5] Abrahams MS, Horn JL, Noles LM, et al. Evidence-based medicine: ultrasound guidance for truncal blocks. Reg Anaesth Pain Med 2010;35(Suppl 2):S36-42.

[6] Vial F, Mory S, Guerci P, et al. Evaluating the learning curve for the transversus abdominal plane block: a prospective observational study. Can J Anaesth 2015;62(6):627-33.
[7] Wang LZ, Liu X, Zhang YF, et al. Addition of fentanyl to the ultrasound guided transversus abdominis plane block does not improve analgesia following cesarean delivery. Exp Ther Med 2016;11(4):1441-6.

[8] Ammar AS, Mahmoud KM. Effect of adding dexmethasone to bupivacaine on transversus abdominis plane block for abdominal hysterectomy: a prospective randomized controlled trail. Saudi J Anaesth 2012;6(3):229-33.

[9] Almarakbi WA, Kaki AM. Addition of dexmeditomidine to bupivacaine in transversus abdominis plane block potentiates post-operative pain relief among abdominal hysterectomy patients: a prospective randomized controlled trail. Saudi J Anaesth 2014;8(2):161-6.

[10] Rana S, Verma RK, Singh J, et al. Magnesium sulphate as an adjuvant to bupivacaine in ultrasound guided transversus abdominis plane block in patients scheduled for total abdominal hysterectomy under subarachnoid block. Indian J Anaesth 2016;60(3):1749. 